\title{
Experimental and numerical study of the joinability of sheets by sheet-bulk forming
}

\author{
I. M. F. Bragança, M. A. R. Loja, C. M. A. Silva, L. M. Alves \& P. A. F. Martins
}

To cite this article: I. M. F. Bragança, M. A. R. Loja, C. M. A. Silva, L. M. Alves \& P. A. F. Martins (2019) Experimental and numerical study of the joinability of sheets by sheet-bulk forming, International Journal for Computational Methods in Engineering Science and Mechanics, 20:4, 283-292, DOI: $10.1080 / 15502287.2019 .1644391$

To link to this article: https://doi.org/10.1080/15502287.2019.1644391

曲 Published online: 25 Jul 2019.

Submit your article to this journal $\pi$

Џ Article views: 67

Q View related articles ¿

View Crossmark data ¿

Citing articles: 1 View citing articles $\sqsubset$ 


\title{
Experimental and numerical study of the joinability of sheets by sheet-bulk forming
}

\author{
I. M. F. Bragança $a^{a, b} \mathbb{D}$, M. A. R. Loja ${ }^{a, b}$ (D), C. M. A. Silva ${ }^{b}$ (D) L. M. Alves $^{b}$ (D), and P. A. F. Martins ${ }^{b}$

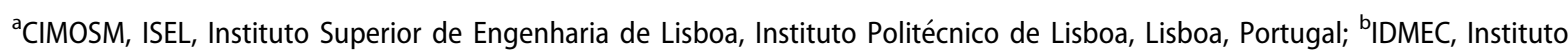 \\ Superior Técnico, Universidade de Lisboa, Lisboa, Portugal
}

\section{ABSTRACT}

The authors present an innovative mechanical joining process that allows to connect perpendicular sheets to one another. This study is focused on joining similar and dissimilar sheets, based on sheet-bulk forming technology, and it is supported by experimental data and numerical simulation. Destructive tensile tests of different joined materials were performed to determine the maximum force that the joints are capable to withstand without failure. The joining technique should be chosen according to the materials joint combination. The two-stages technique could be a valid option to overcome the clearance between the plastically deformed polycarbonate tenon and aluminium mortise.

\section{KEYWORDS}

Experimentation; finite element analysis; sheet-bulk forming; joining by plastic deformation; dissimilar materials

\section{Introduction}

Nowadays, the growing demand for consumer goods has enhanced the development of new materials and products, leading to emerge innovative manufacturing techniques, such as new metal forming and joining processes. In fact, the need for processing new alloys and joining dissimilar materials is responsible for the establishment of new sheet-bulk forming and joining by plastic deformation processes.

Plastic deformation is commonly used in forming processes to manufacture mechanical components, nevertheless it can also be applied to join parts. Additionally, comparing with conventional techniques, like welding, Figure 1(a), adhesive bonded joints that normally require surface preparation, Figure 1(b), these processes have the advantage of joining a wide range of materials (including dissimilar materials), showing less embrittlement, distortion, tensile residual stress and higher process reliability among other benefits. Although mechanical joint with fasteners or rivets is also widely used, it involves extra mass to the components derived from the utilisation of brackets, clips, stiffeners, washers, screws, nuts and rivets, Figure 1(c).

In this context, the authors present an environmentfriendly mechanical joining process, that allow to connect two sheets perpendicular to one another by sheetbulk forming. This process could be considered as a variant of the traditional 'mortise-and-tenon' joint widely used in wood parts Figure 1(d). Sheet-bulk metal forming process allow to manufacture parts with local thickening, thinning or functional features such as teeth, ribs and may possibly be used to join parts $[1,2]$.

This investigation, supported by experimental data and numerical simulation, is focussed on joining similar and dissimilar sheets by sheet-bulk forming. This methodology that draws from material characterisation to finite element modelling allows to increase process know-how, validate software use on this forming technology and improve the technological practice during its development. Through the numerical simulation software I-form, it was possible to predict the load-displacement evolution, the maximum force required from the hydraulic press and, extremely important, the joint feasibility.

The joining method as well the punches' design are also discussed and special emphasis is placed on the divided plastic flow in order to reduce the initial compression forces and reduce elastic recovery, alloying to eliminate a possible clearance in the joint.

\section{Experimentation}

\subsection{Mechanical characterisation: stress- strain curves}

The stress-strain curve of the aluminium alloy EN AW $5754 \mathrm{H} 111$ sheets with $5 \mathrm{~mm}$ thickness was

CONTACT I. M. F. Bragança ibraganca@dem.isel.pt @ CIMOSM, ISEL, Instituto Superior de Engenharia de Lisboa, Instituto Politécnico de Lisboa, Rua Conselheiro Emídio Navarro, Lisboa 1959-007, Portugal.

Color versions of one or more of the figures in the article can be found online at www.tandfonline.com/ucme.

(c) 2019 Taylor \& Francis Group, LLC 


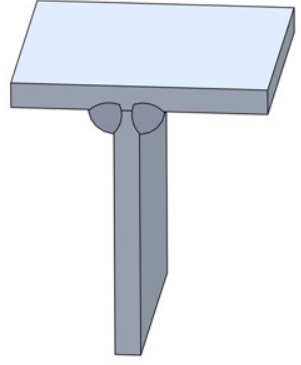

(a)

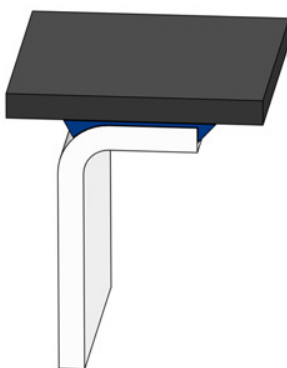

(b)

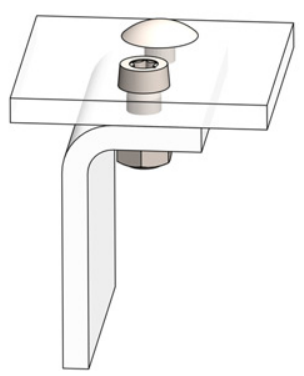

(c)

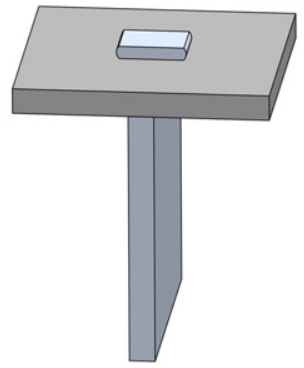

(d)

Figure 1. Types of joints to connect two sheets perpendicular to one another: (a) welded joint; (b) adhesive bonded joint; (c) mechanical fastened or riveted joint; (d) the proposed 'mortise-and-tenon' joint.

performed by means of stack compression tests while polycarbonate, since is pressure sensitive, was determined by means of compression and tensile tests [3]. The cylinder test specimens were assembled by pilling up 3 circular discs machined out of the supplied aluminium and polycarbonate sheets by a hole-saw and turning. To determine the tensile stress-strain curve, the test specimens were machined out of the supplied sheets in accordance to the ASTM D 638 standards. The compression tests were performed at room temperature on a hydraulic testing machine (Instron SATEC $1200 \mathrm{kN}$ ) and the resulting stress-strain curves are shown in Figure 2.

\subsection{Work plan, methods and procedures}

The laboratory work is performed combining experimental investigation and finite element modelling. To accomplish this, a laboratory tool was designed to test the specimens, identify the major process parameters and understand their influence on the overall joining feasibility. Special emphasis is placed on the utilisation of V-shaped punches (acts like a 'chisel') at the early stages of upsetting in order to reduce the initial compression forces, change head design and reduce the material elastic recovery.

The study was focussed on the connection of polymer and metal sheets perpendicular to one another, joining different combinations.

The tests were performed in the tool developed, schematic represented in Figure 3, highlighting the forming punches ('P1':flat and 'P2':V-shaped) and the blank holder that allow to clamp the lower sheets firmly. The tool installed in testing machine Instron SATEC $1200 \mathrm{kN}$ where carried out in displacement control at $5 \mathrm{~mm} / \mathrm{min}$ and room temperature.

The unit cell that fixes longitudinally in position two sheets perpendicular to one another is characterised by a rectangular cavity, from now on called

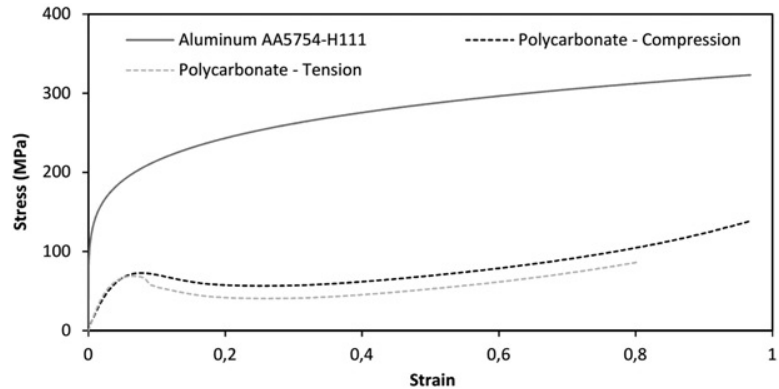

Figure 2. Polycarbonate and aluminium AA5754-H111 sheets stress-strain curves.

'mortise', and a tenon longer than wider that passes completely through the other sheet. The mechanical locking is performed by a compression force perpendicular to the thickness direction that plastically deform the free length of the tenon along $z$-axis.

Firstly, the authors studied the upset compression of the polycarbonate and aluminium tenons. This allows to determine the process window without signs of plastic instability and risk of failure by buckling. Different tenons' length-to-width ratio were tested in both materials, setting the width twice the sheet thickness $t_{0} / w_{0}=0.5$ (Figure 3 ).

The connection of two individual sheet specimens by means of the new proposed mechanical joining process, takes different parameters in consideration, the length-to-width ratio $l_{f} / w_{0}$, material and the geometry of the punch. The authors present two techniques, the first performed with just one-stage (without performing) and second with two-stages (with performing). The later involved the utilisation of flat (P1) and V-shaped (P2) punches, Figure 3, in order to evaluate the influence of promoting and facilitating the occurrence of divided flow in the plastically deformed tail of the tenon.

Destructive testing is carried out to characterise the overall performance of the new proposed 'mortise- 


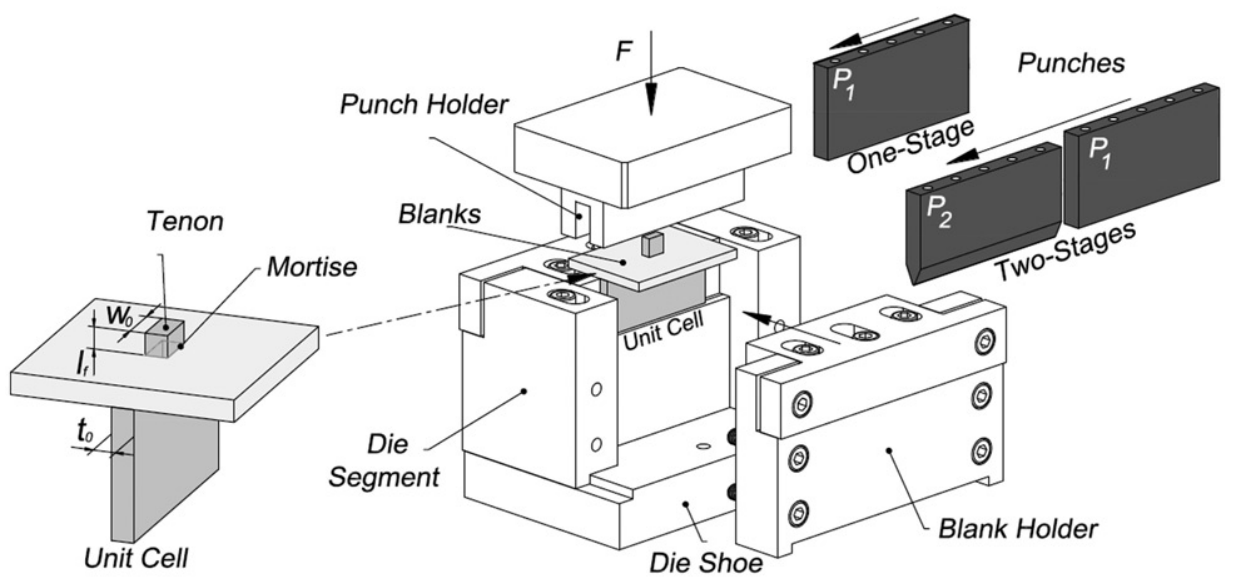

Figure 3. Laboratory tool schematic representation for joining a unit cell of two sheets perpendicular to one another with onestage and two-stages technique.

and-tenon' joint and determining the maximum force to detach the two sheets.

\section{Numerical modelling}

\subsection{Extended finite element flow formulation to pressure sensitive polymers}

The investigation on the joining of metal, polymer and polymer-metal sheets perpendicular to one another was supported by numerical simulations with the in-house finite element computer programme Iform. I-form is based on the finite element flow formulation and includes an extension to pressure-sensitive polymers that allows modelling metal and polymer deformable objects simultaneously [4].

The extension of the finite element flow formulation to pressure-sensitive polymers utilises the yield function $F\left(\sigma_{i j}\right)$ proposed by Caddell et al. [5] for modelling cold plastic deformation of polymers with strength-differential effects resulting from the difference between tensile $\sigma_{T}$ and compressive $\sigma_{C}$ flow stresses,

$$
F\left(\sigma_{i j}\right)=\bar{\sigma}^{2}-\sigma_{C} \cdot \sigma_{T}+\left(\sigma_{C}-\sigma_{T}\right) \sigma_{k k}=0
$$

where $\quad \bar{\sigma}=\sqrt{\frac{3}{2} \sigma_{i j}^{\prime} \sigma_{i j}^{\prime}}$ is the effective stress and $\sigma_{k k}=\delta_{i j} \sigma_{i j}$.

However, and in contrast to what is commonly done in metals, the extension to pressure-sensitive polymers makes use of a non-associated flow rule in which the plastic potential $Q$ is not related to the yield function $F\left(\sigma_{i j}\right)$ but to the second invariant of the deviatoric stress tensor $Q=J_{2}$,

$$
\dot{\varepsilon}_{i j}^{p}=\dot{\lambda} \frac{\partial Q\left(\sigma_{i j}\right)}{\partial \sigma_{i j}}
$$

where $\dot{\lambda}$ is a scalar factor of proportionality.
This methodology has been successfully applied by other authors to ensure incompressibility in the cold forming of pressure-sensitive polymers $[6,7]$ and to perform numerical simulations with finite element computer programmes [8].

The finite element flow formulation giving support to $\mathrm{i}$-form is built upon the following extended variational that allows metals and polymers to be treated simultaneously,

$$
\begin{aligned}
\Pi= & \int_{V} \bar{\sigma} \dot{\bar{\varepsilon}} d V+\frac{1}{2} K \int_{V} \dot{\varepsilon}_{v}^{2} d V-\int_{S_{T}} T_{i} u_{i} d S \\
& +\int_{S_{f}}\left(\int_{0}^{\left|u_{r}\right|} \tau_{f} d u_{r}\right) d S
\end{aligned}
$$

where, $\dot{\bar{\varepsilon}}$ is the effective strain rate, $\dot{\varepsilon}_{v}$ is the volumetric strain rate, $K$ is a large positive constant enforcing the incompressibility constraint of both metals and polymers and $V$ is the control volume limited by the surfaces $S_{U}$ and $S_{T}$, where velocity and traction are prescribed. Friction at the contact interfaces $S_{f}$ is treated as a traction boundary condition and the additional power consumption term is modelled through the utilisation of the law of constant friction $\tau_{f}=m k$ [9]. Further details on the finite element flow formulation and on its computer implementation can be found in reference [10].

To investigate the tenon critical length length-towidth ratio $l_{f} / w_{0}$ to generate plastic instability and out-of-plane buckling it was employed finite element modelling, using three-dimensional and simplified two-dimensional models under plane strain deformation conditions and the sheets were modelled as deformable objects. When the simulations make use of three-dimensional models, the specimens were 


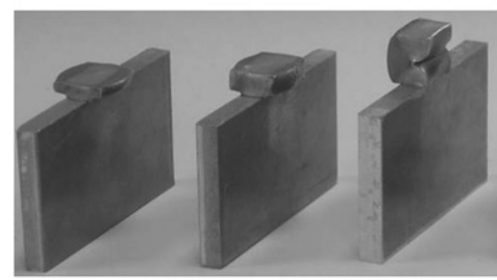

(a)

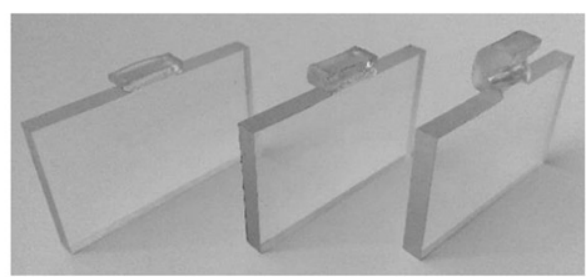

(b)

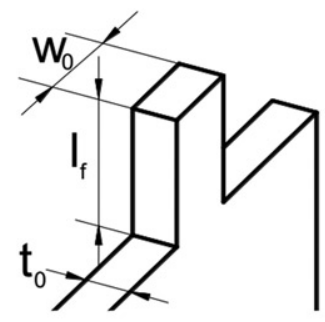

\begin{tabular}{|c|c|c|c|}
\cline { 3 - 4 } \multicolumn{2}{c|}{} & \multicolumn{2}{c|}{ Material } \\
\cline { 3 - 4 } \multicolumn{2}{c|}{} & Aluminium & Polycarbonate \\
\hline \multirow{4}{*}{$l_{f} / w_{0}$} & $\mathbf{0 . 5}$ & Symmetric & Symmetric \\
\cline { 2 - 4 } & $\mathbf{1 . 0}$ & Symmetric & Symmetric \\
\cline { 2 - 4 } & $\mathbf{1 . 5}$ & Symmetric & Buckling \\
\cline { 2 - 4 } & $\mathbf{2 . 0}$ & Buckling & Buckling \\
\hline
\end{tabular}

(c)

Figure 4. Specimens with different length-to-width ratios $I_{f} / w_{0}$ loaded in uniaxial compression perpendicular to the sheet thickness $\left(t_{0} / w_{0}=0.5\right)$. (a) Photographs of compressed aluminium specimens. (b) Photographs of compressed polycarbonate specimens. (c) Summary of the observed deformation modes.

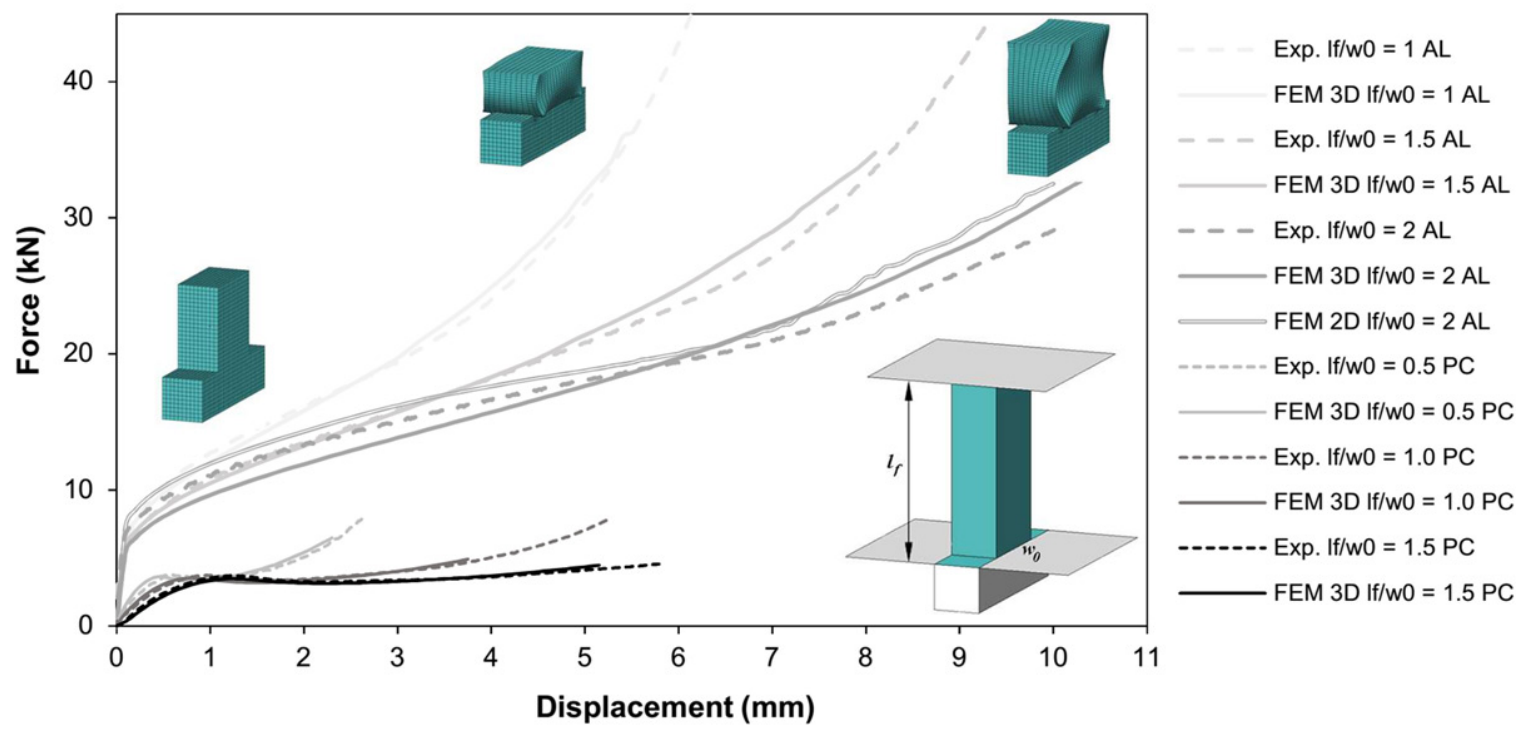

Figure 5. Experimental and finite element predicted evolution of the force with displacement during the upset compression of polycarbonate and aluminium tenons with different length-to-width ratios.

discretized by means of hexahedral elements and the blank holder and punch were discretized by means of contact-friction spatial linear triangular elements. As will be seen later, the simplified $2 \mathrm{D}$ models provide results near to the experimental observations and force evolutions and the complete simulations just take a few minutes. In Figure 5 the images show the initial and final deformed meshes for two different test specimens which give rise to a symmetric plastic deformation and non-symmetrical upset deformation resulting from out-of-plane buckling.
Finite element analysis was also employed to simulate the joining of the individual sheet specimens of a 'unit cell' locked by sheet-bulk forming, made from aluminium, polycarbonate and combinations of both. The experienced gained in the upset compression of the tenons was special important, because allowed to better understand the process and, if considered viable, permitted to simplify the simulation modelling, building two-dimensional models, halving the two sheets lengthwise and discretizing the resulting cross section by means of 
quadrilateral elements under plane strain deformation conditions.

\section{Results and discussion}

\subsection{Upset compression of the tenon}

To characterise the process and identify the joinability window, the first task was to determine the critical length-to-width ratio $l_{f} / w_{0}$ that gives rise to plastic instability by upset compression of the tenon. To achieve that, different ratios where tested with aluminium, Figure 4 (a), and polycarbonate, Figure 4(b). There are typically two deformation modes, symmetric and asymmetric, resulting from instability and out-ofplane buckling [11], characterised by two different trends of the force-displacement evolution.

Figure 4(c) summarises the observed deformation modes and allows identifying the acceptable free tenon length to join sheets by sheet-bulk forming without instability.

In spite of the experimental conditions and geometries be exactly the same, the critical instability arise with different length-to-width ratio depending on the test specimen material. For polycarbonate, the critical instability arises when $1.0<l_{f} / w_{0} \leq 1.5$, but for aluminium alloy it arises when $1.5<l_{f} / w_{0} \leq 2.0$. The ratios before this instability give a rise to symmetric deformations and are suitable for the desired joints, instead of the non-symmetrical deformations because they are unsuitable to fix longitudinally in position two sheets perpendicular to one another.

Figure 5 shows the experimental and finite element predicted evolutions of the force with the $Z$-axis displacement. For aluminium experimental force evolution, until reaching the critical value, a steep rise is followed by a monotonic increase. The occurrence of out-of-plane buckling failure promotes a different force evolution, after the first step increase, depending on the free tenon length, the compression force may remain approximately constant or may even decrease. Afterward the strain hardening and the contact area with the punch grow, increasing the compression force.

Although the experimental force evolution of the polymer specimens be similar, some differences should be emphasised. Independent of the deformation mode, the initial force increases up to a maximum value, then decreases slightly and starts to rise again until the end of the test. This behaviour is similar to the previously determined stress-strain curve of polycarbonate. The major difference when is reached the critical instability is related with the lower increase rate of the compression force.
Figure 5 also shows that the finite element force evolution obtained from two-dimensional and threedimensional simulation could predict quite well the force variations with the punch displacement, although the plain strain simplification in two-dimensonal simulation give a slightly overestimation in the beginning of the test.

\section{2. 'Mortise and tenon' joints without preforming}

This investigation is focussed on joining similar and dissimilar sheets perpendicular to one another, based on sheet-bulk forming. Bearing in mind that, it was chosen a constant length-to-width $l_{f} / w_{0}$ ratio that ensures symmetric upset compression of tenons, equal to 0.5 , since it promotes less material waste and lower compression forces. Thus, the aim now is to discuss the feasibility of the new mechanical joining process to connect sheets with different materials combinations, employing just one deformation stage with a flat punch (without preforming).

Four different combinations are presented, using two sheets of the same material, aluminium (Tenon_AL Mortise_AL) and Polycarbonate (Tenon_PC Mortise_PC), and two connections with arrangements of both materials (Tenon_PC Mortise_AL; Tenon_AL Mortise_PC). All connections tested were well performed and do not present defects like the upper sheet bent or defects involving buckling of the tenons [2], showing agreement with previous observations in Section 4.1.

Figure 6 shows the experimental and finite element predicted evolutions of the force with displacement for different testing conditions. In all cases the experimental maximum force is observed at the end of the unit cell joining, attaining the deformed flat surface with approximately some thickness. When the tenon is aluminium, the compression forces are much higher and with step increase in the early stage, on the other end for polycarbonate tenons, lower compression forces are required to produce the unit cell, despite the total displacement to produce the mechanical lock being identical.

The material of the mortise has also a major influence in the maximum compression force independently of tenons' materials, but far noticeable when testing the aluminium tenon. As observed in Figure $6(a, b)$, the mortise tends to deform when higher forces are applied, especially if the material is less resistance (see cross section of Tenon_AL Mortise_PC in Figure 6(c)). This observation is supported by the stress-strain curves of both materials, but could also 


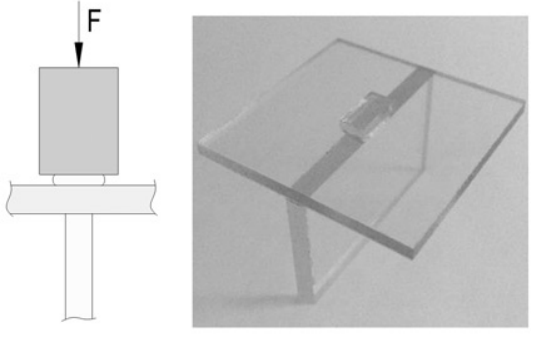

(a)

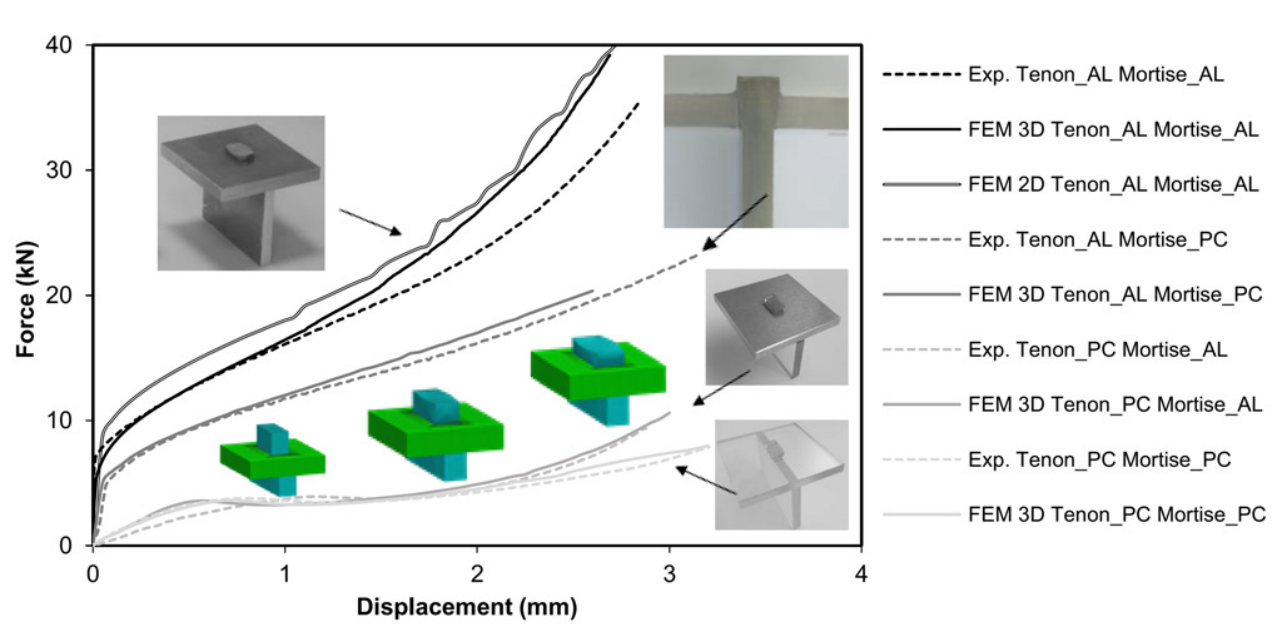

(c)

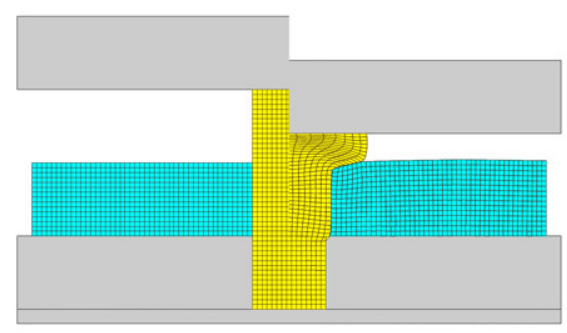

(b)

Figure 6. Joining sheets with different materials perpendicular to one another by means of a 'mortise-and-tenon' joint locked by sheet-bulk forming. (a) Schematic representation of the joining process without preforming and photograph showing polycarbonate sheets joint. (b) Finite element predicted cross section of aluminium sheets joint $l_{f} / w_{0}=0.5$. (c) Experimental and finite element predicted evolution of the force with displacement for various materials combination of sheets.

be understood evaluating the project area of the tail, strain hardening and material flow. So, with aluminium tenons, the forces required to lock the sheets are higher and polycarbonate mortises promotes lower compression forces. The forces evolutions are also different and depend mainly from the material of the tenon, showing similar trends to the observed in Section 4.1. The aluminium mortise tends to influence the final evolution of the connection showing a growing rate in the end, and when joining the aluminium tenons it is also observed a significant difference of the force along the connection.

The numerical results support and validate the experimental investigation. A comparison of twodimensional and three-dimensional finite element predicted evolutions of the force with displacement presented in Figures 5 and 6, allows concluding that twodimensional models can also be successfully utilised for modelling the instability tests and joining operations under plane strain deformation conditions.

However, the small overestimation provided by finite elements could be related to a stiffer physical model than the real experiment, as a result of a significant amount of material being replaced by fixed displacement boundary conditions.

The good agreement between the numerical and experimental results, the higher time consuming of the three-dimensional finite element simulation and the symmetry deformation, shows that the two-dimensional simulations could be a better solution to implement in industrial applications.

\section{3. 'Mortise and tenon' joints with preforming}

In order to understand the possibility to reduce the initial forces, the clearance between some connections and the risk of failure by buckling at the early stages of deformation, a two-stages technique involving preforming with a V-shaped punch (P2) was carried out before upsetting and locking the joint with the flat punch (P1, see Figure 3). The V-shaped punch acts as a chisel and promotes divided material flow along its central edge to increase the width of the upper tail of the tenon (Figure $7(\mathrm{a}, \mathrm{b})$ )).

Figure 7(c) shows the experimental and finite element predicted evolutions of the force with 

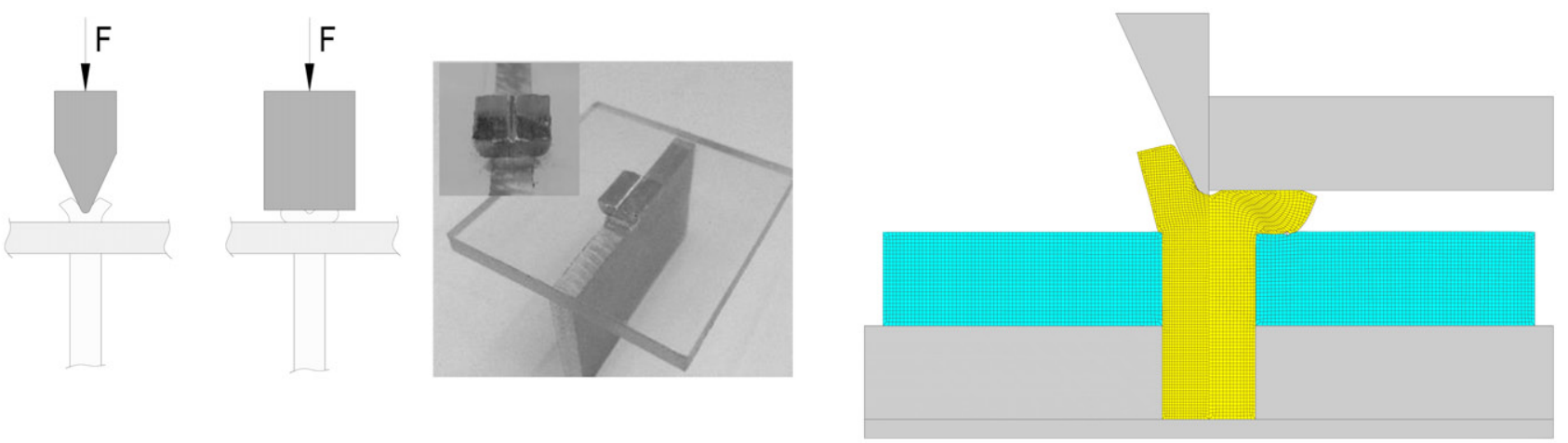

(a)

(b)

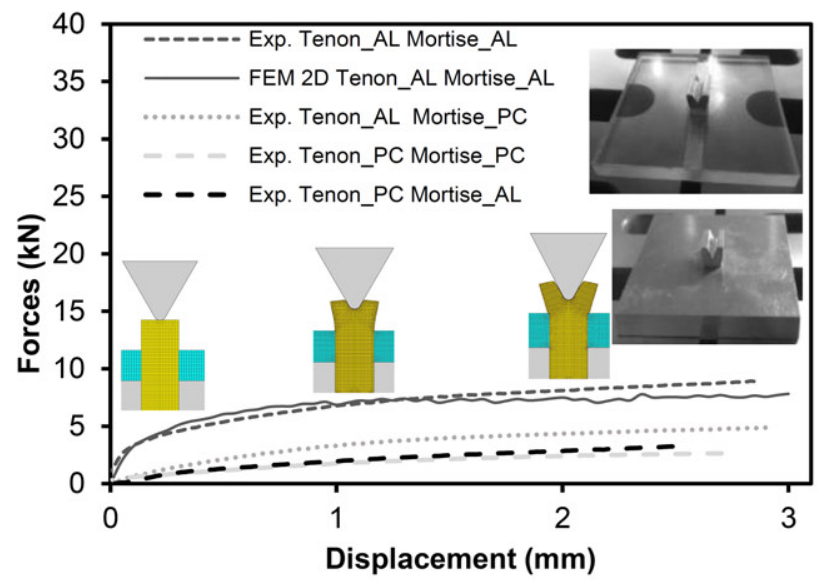

(c)

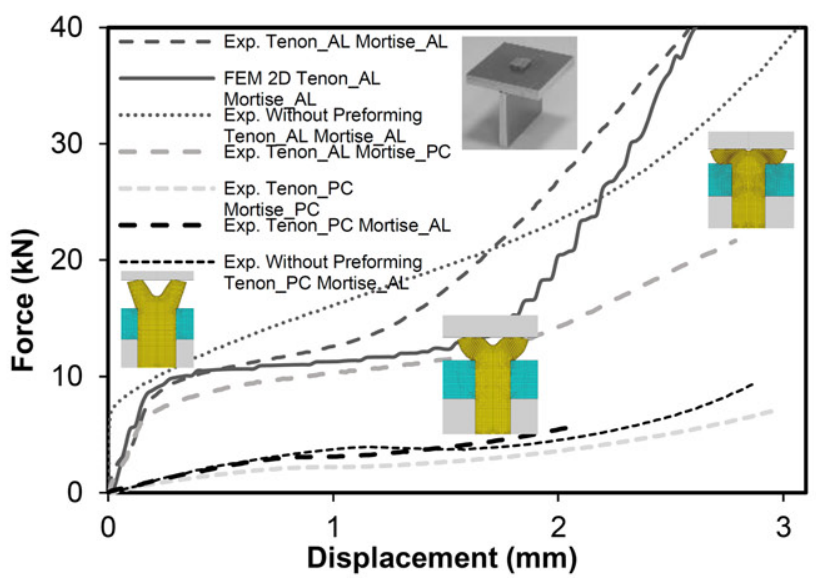

(d)

Figure 7. Joining sheets with different materials perpendicular to one another by means of a 'mortise-and-tenon' joint locked by sheet-bulk forming. (a) Schematic representation of the joining process with a V-shaped preforming punch and Photograph showing aluminium polycarbonate sheets joint $l_{f} / w_{0}=0.5$. (b) Finite element predicted cross section showing aluminium sheets joint $I_{f} / w_{0}=0.5$. (c) Experimental and finite element predict evolutions of the force with displacement for a unit cell with preforming by means of a V-shaped punch (P2). (d) Experimental and finite element predict evolutions of the force with displacement for a unit cell with preforming by means of a Flat punch (P1) after first stage compression (P2). Joints produced without preforming are also presented for comparison.

displacement using a V-shaped punch. The reduction in force derived from the utilisation of a $\mathrm{V}$-shape punch at the early stages of deformation, may be important for reducing the deformation inside the mortise, promoting less locking defects, or could eventually prevent the use of clamps to rigidly fix the tenons.

Figure $7(\mathrm{~d})$ shows the experimental and finite element predict evolutions of the force with displacement for a unit cell by a flat punch after a performing by means of a V-shaped punch. Comparing with the one-stage specimen, the initial force at early stages is lower, but in the end of the locking, the force is similar. However, this two-stages technique is a good solution to eliminate the clearance observed in hybrid joints due to the different elastic recovery of the materials. In fact, the elastic recovery of polycarbonate tenons may give rise to a small clearance between the deformed tenon and the aluminium mortise. This may not compromise the maximum tensile force that the joint is capable to withstand without failure, but could be unacceptable for applications in which the connection must be rigidly clamped.

In Figure 7, the finite element method allows to simulate the deformation mechanism of all process stages, namely the divided flux and the flat head during upsetting. The force evolution with punch displacement is quite well predicted such as the maximum loading force.

Figure 8 shows the difference between the two methodologies studied to join the unit cell and helps to understand that the $\mathrm{V}$-shaped punch that promotes 


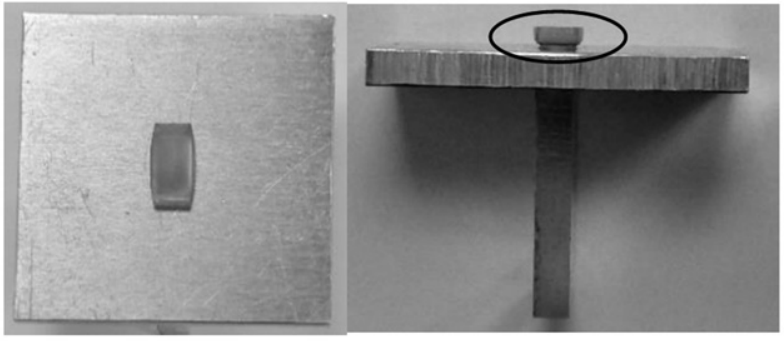

(a)

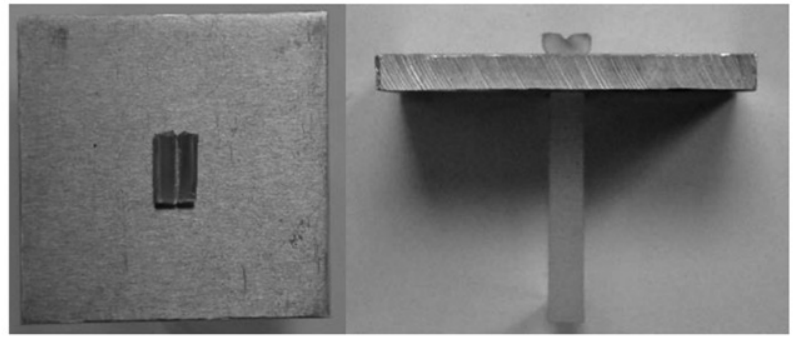

(b)

Figure 8. One-stage and two-stage variant of the joining process to eliminate the elastic recovery of polycarbonate tenons. (a) Joint showing a clearance between the plastically deformed tenon and the mortise. (b) Joint produced by the two-stages variant of the process without clearance.

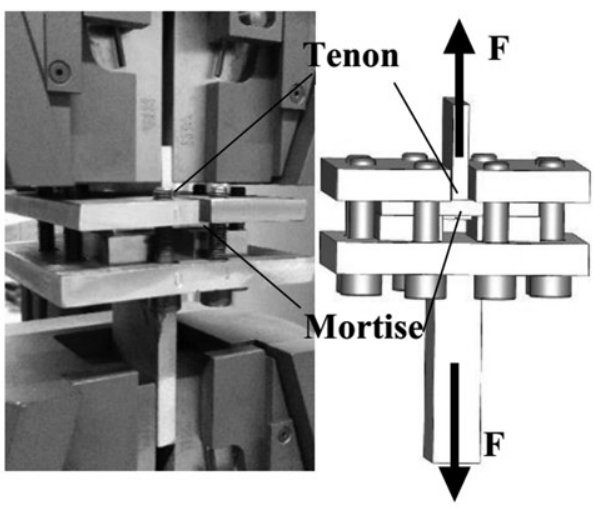

(a)

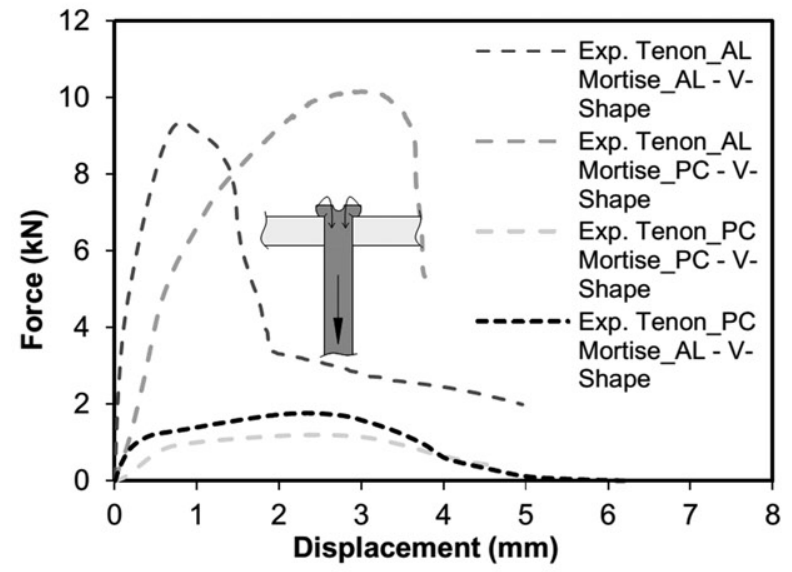

(c)
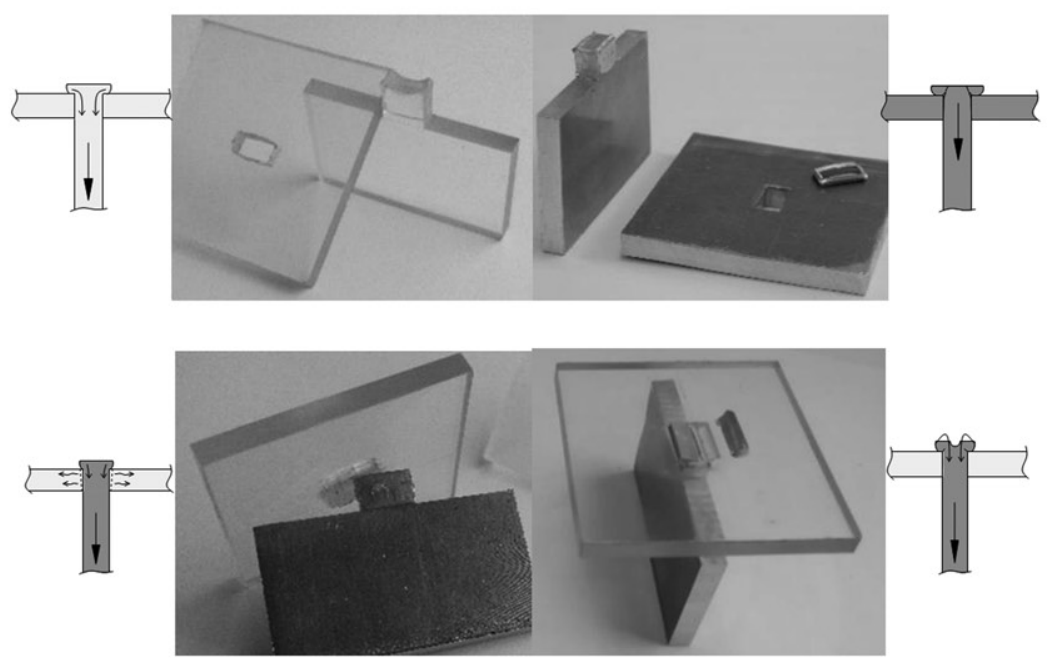

(b)

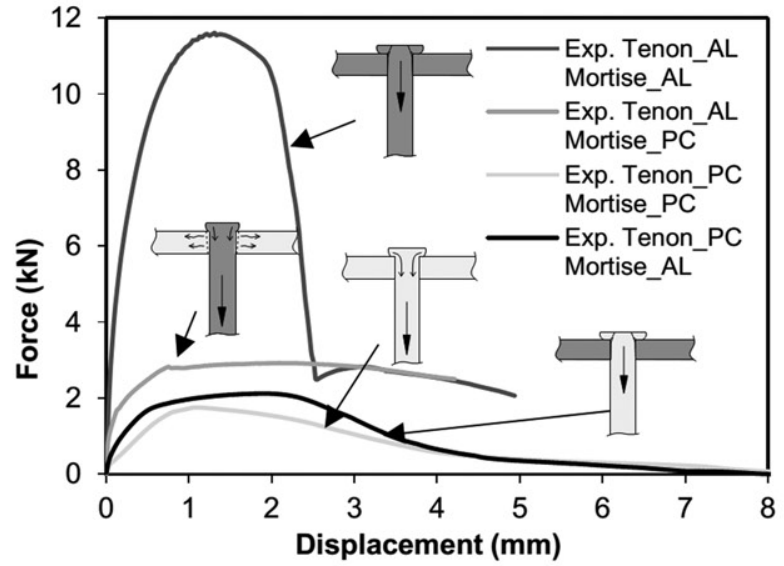

(d)

Figure 9. Destructive testing of the new proposed 'mortise-and-tenon' joint with and without preforming by means of a V-shaped punch. (a) Schematic representation of the experimental setup for tensile testing. (b) Schematic representation and Photographs of different joints. (c) Experimental evolution of the force with displacement for different material combination with preforming by means of a V-shaped punch. (d) Experimental evolution of the force with displacement for different material combination without preforming by means of a V-shaped punch. 
the initial divided flux may also be used in materials with higher elastic recovery.

\subsection{Destructive testing of the 'mortise-and- tenon' joint}

The maximum force that the joined unit cell can withstand was evaluated by destructive tensile (pullout) tests. An experimental test setup was developed, as shown in Figure 9(a), which was designed to prevent the deformation of the sheets by bending during the tests.

The experimental evolution of the tensile force with displacement of the different joints is shown in Figure $9(c, d)$. As seen, the tensile force required to destroy the joints depends significantly of the joint materials and joining technique.

Observing Figure $9(\mathrm{~b}-\mathrm{d})$, could be considered that there are two main different trends in the failure mechanism. In case of joints with aluminium mortise produced with a one-stage technique, the test allows concluding that failure occurs due to necking and/or cracking of the tenon. In contrast, the joints produced by two-stages technique and polycarbonate mortise joints produced with a one-stage technique, failure is accomplished by drawing of the flat-shaped surface head of the tenon through the mortise.

There are some differences in the overall performance of the joints that were produced with and without preforming. Although there are exceptions after referred, when a two-stages technique (V-shape plus flat plate) is used, the maximum force is $\sim 15$ to $20 \%$ lower than the force supported by the sheets joined with one-stage technique.

Comparing the maximum force values that the joints withstand when using aluminium tenons and the two-stages technique, see Figure 9(c), it is possible to verify that the maximum tensile force is approximately equal independently of being tested with an aluminium or polycarbonate mortise. Although the mechanical properties of the mortise be significantly different, during the tensile destructive tests a similar deformation occurs and primarily in the tenon's tail.

Comparing the maximum force values between the joints preformed with the one-stage or two-stages technique, it is also possible to verify that the connections manufactured with the $\mathrm{V}$-shape punch and an aluminium tenon, show much higher mechanical tensile strength values. This difference should be related to the plastic deformation preformed during the connection. In fact, when polycarbonate mortise is used, which has a lower mechanical resistance than aluminium mortise, the deformation essentially results in an increase in the thickness of the entire height of the tenon, as shown in Figure 6(c). On the other hand, due to the $\mathrm{V}$-shape punch geometry, a consequent reduction of the initial compression force is observed and plastic deformation occurs essentially in the free part of the tenon instead inside the mortise changing its geometry, as observed in Figure 7(a).

\section{Conclusions}

The proposed mechanical joining process is an alternative to the existing solutions that allows connecting sheets with similar and dissimilar materials perpendicular to one another.

Initially upset compression tests were performed to identify the process window that is characterised by length-to-width ratio and material of the tenon. These variables influence the development of two modes of deformation, symmetric and asymmetric.

The joining feasibility of sheets perpendicular to one another with different materials were evaluated. Experimental tests show that force evolution is different, depending mainly from the tenons' material and the finite element force obtained from two-dimensional and three-dimensional simulation could predict the force evolution with the punch displacement as well the deformation mechanism of all the joining operation stages.

The utilisation of preforming by means of a Vshaped punch diminishes the upset compression forces at the early stages of deformation. The experimental evolution of the force with displacement during destructive testing (pull-out) do not reveal considerable differences between the 'mortise-andtenon' joints produced with and without preforming (one-stage or two-stages techniques), but a significant exception exists if a joint with aluminium tenon and polycarbonate mortise due to the final head geometry.

Excluding this case, the first choice for an industrial application should be placed on 'mortise-andtenon' joints locked by sheet-bulk forming without preforming (one-stage), unless a different head design is desired or some clearance between sheets is observed.

\section{Acknowledgments}

The authors would like to acknowledge the support provided by the Project IPL/2016/CompSBJ_ISEL, by Fundação para a Ciência e a Tecnologia of Portugal and IDMEC under LAETA - UID/EMS/50022/2019 and PDTC/EMSTEC/0626/2014. The authors would also like to 
acknowledge the support provided by MCG - Mind for Metal, Carregado, Portugal.

\section{ORCID}

I. M. F. Bragança (D) http://orcid.org/0000-0001-5409-619X

M. A. R. Loja (D) http://orcid.org/0000-0002-4452-5840

C. M. A. Silva (ID http://orcid.org/0000-0003-3837-5185

L. M. Alves (D) http://orcid.org/0000-0002-7170-0333

P. A. F. Martins iD http://orcid.org/0000-0002-2630-4593

\section{References}

[1] M. Merklein et al., "Bulk forming of sheet metal," CIRP Annals-Manufacturing technol., vol. 61, no. 2, pp. 725-745, 2012. DOI: 10.1016/j.cirp.2012.05.007.

[2] I. Bragança, C. Silva, L. Alves, and P. Martins, "Joining sheets perpendicular to one other by sheetbulk metal forming," Int $J$ Adv Manufacturing Technol, vol. 89, no. 1-4, pp. 77-86, 2017. DOI: 10 . 1007/s00170-016-9083-5.

[3] C. Silva, M. Silva, L. Alves, and P. Martins, "A new test for determining the mechanical and fracture behaviour of materials in sheet-bulk metal forming," J Mater Design Appl, vol. 231, no. 8, pp. 693-703, 2017. DOI: $10.1177 / 1464420715616140$

[4] L. Alves, and P. Martins, "Nosing of thin-walled PVC tubes into hollow spheres using a die," Int $J$ Advanced Manufacturing Technol., vol. 44, no. 1-2, pp. 26-37, 2009. DOI: 10.1007/s00170-008-1805-x.

[5] R. Caddell, R. Raghava, and A. Atkins, "Pressure dependent yield criteria for polymers," Materials Sci
Eng., vol. 13, no. 2, pp. 113-120, 1974. DOI: 10. 1016/0025-5416(74)90179-7.

[6] J. Lee, and J. Oung, "Yield functions and flow rules for porous pressure-dependent strain-hardening polymeric materials," J Appl Mech, vol. 67, no. 2, pp. 288-297, 2000. DOI: 10.1115/1.1305278.

[7] Y. Sanomura, and K. Hayakawa, "Modification of isotropic hardening model and application of kinematic hardening model to constitutive equation for plastic behavior of hydrostatic-pressure-dependent polymers," J Soc Mater Sci Jpn, vol. 53, no. 2, pp. 143-149, 2004. DOI: 10.2472/jsms.53.143.

[8] Y. Zhu, Y. Liu, H. Li, and H. Yang, "Comparison between the effects of PVC mandrel and mandrelcores die on the forming quality of bending rectangular H96 tube," Int J Mech Sci, vol. 76, pp. 132-143, 2013. DOI: 10.1016/j.ijmecsci.2013.09.011.

[9] I. Bragança, C. Silva, L. Alves, and P. Martins, "Ligthweight joining of polymer and polymer-metal sheets by sheet-bulk forming," J Clean Prod, vol. 145, pp. 96-104, 2017.

[10] C. Nielsen, W. Zhang, L. Alves, N. Bay, and P. Martins, Modelling of Thermo-Electro-Mechanical Manufacturing Processes with Applications in Metal Forming and Resistance Welding. London, UK: Springer-Verlag, 2013.

[11] S. Patel, and A. Sheikh, "Buckling response of laminated composite stiffened plates subjected to partial in-plane edge loading," Int J Comput Meth Eng Sci Mech, vol. 17, no. 5-6, pp. 322-338, 2016. DOI: 10. $1080 / 15502287.2016 .1231235$. 